\title{
Hydrophilic or Lipophilic Statins?
}

\author{
Elisenda Climent ${ }^{1,2}$, David Benaiges ${ }^{1,2,3}$ and Juan Pedro-Botet ${ }^{1,2,3 *}$ \\ ${ }^{1}$ Department of Endocrinology and Nutrition, Hospital del Mar, Barcelona, Spain, ${ }^{2}$ Department of Medicine, Universitat \\ Autònoma de Barcelona, Campus Universitari Mar, Barcelona, Spain, ${ }^{3}$ Institut Hospital del Mar d'Investigacions Mèdiques \\ (IMIM), Barcelona, Spain
}

Drugs can be classified as hydrophilic or lipophilic depending on their ability to dissolve in water or in lipid-containing media. The predominantly lipophilic statins (simvastatin, fluvastatin, pitavastatin, lovastatin and atorvastatin) can easily enter cells, whereas hydrophilic statins (rosuvastatin and pravastatin) present greater hepatoselectivity. Although the beneficial role of statins in primary and secondary cardiovascular prevention has been unequivocally confirmed, the possible superiority of one statin or other regarding their solubility profile is still not well-established. In this respect, although some previously published observational studies and clinical trials observed a superiority of lipophilic statins in cardiovascular outcomes, these results could also be explained by a greater low-density lipoprotein cholesterol reduction with this statin type. On the other

OPEN ACCESS

Edited by:

Ricardo Gómez-Huelgas, Regional University Hospital of

Malaga, Spain

Reviewed by:

Ali Javaheri,

Washington University School of Medicine in St. Louis, United States

Daisy Sahoo,

Medical College of Wisconsin, United States

${ }^{*}$ Correspondence:

Juan Pedro-Botet

86620@parcdesalutmar.cat

Specialty section:

This article was submitted to Lipids in Cardiovascular Disease, a section of the journal Frontiers in Cardiovascular Medicine

Received: 29 March 2021 Accepted: 28 April 2021 Published: 20 May 2021

Citation:

Climent $E$, Benaiges $D$ and Pedro-Botet J (2021) Hydrophilic or Lipophilic Statins? Front. Cardiovasc. Med. 8:687585. doi: $10.3389 / f C v m .2021 .687585$ hand, previous studies reported conflicting results as to the possible superiority of one statin type over the other regarding heart failure outcomes. Furthermore, adverse events with statin therapy may also be related to their solubility profile. Thus, the aim of the present review was to collect clinical evidence on possible differences in cardiovascular outcomes among statins when their solubility profile is considered, and how this may also be related to the occurrence of statin-related adverse effects.

Keywords: adverse effects, cardiovascular disease, hydrophilic, lipophilic, pleiotropic effects, statins

\section{HYDROPHILICITY VS. LIPOPHILICITY}

The classification of drugs as hydrophilic or lipophilic depends on their ability to dissolve in water or in lipid-containing media. In this respect, absorption is faster in lipophilic drugs, whereas the ease for renal excretion is greater in hydrophilic medications.

As most drugs are weak acids or bases, in an aqueous solution they can be present in two phases: ionised or polar and non-ionised or non-polar. The ionised polar fraction is water-soluble whereas the non-ionised is fat-soluble and is the only one that diffuses easily through cell membranes. The degree of molecule ionisation depends on three main factors: their acidic/basic nature, the dissociation constant of the molecule measured by $\mathrm{pK}$ and the $\mathrm{pH}$ of the medium where it is found. However, the latter is the definite determinant of the drug's availability to cross cell membranes and act on diverse tissues. Moreover, the degree of digestive absorption and renal excretion of each drug can be modified by changing the $\mathrm{pH}$ of the medium where it is found (1).

It must also be considered that hydrophilic substances can be excreted without undergoing any transformation. On the other hand, although the kidney can poorly filter ionised molecules (lipophilic), these are mostly reabsorbed back into the tubule. For this reason, most lipophilic substances are metabolised to become more polar metabolites, which then become water-soluble.

Thus, the hydro- or liposolubility of each drug is an aspect that should be carefully considered in clinical practise when deciding on the type of treatment, together with dose adjustment in patients 
with renal failure. In that clinical scenario, lipophilic drugs should be avoided, although other clinical characteristics must also be considered.

\section{HYDROPHILIC VS. LIPOPHILIC STATINS}

Since the introduction of lovastatin in 1987 as the first 3hydroxy-3-methyl-glutaryl-coenzyme A (HMG-CoA) reductase inhibitor approved for human therapy, statins have become the most widely used lipid-lowering drugs with proven effect in cardiovascular disease prevention in different clinical settings $(2-5)$. Statins have been classified in 3 categories based on their potency and efficacy in lowering low-density lipoprotein (LDL) cholesterol concentrations. First-generation statins included lovastatin, pravastatin and fluvastatin, simvastatin and atorvastatin belong to the second generation, and rosuvastatin and pitavastatin to the third.

Structurally, statins have three main parts as detailed in Figure 1: the analogue of HMG-CoA, a complex ring structure which binds the statin molecule to the HMG-CoA reductase enzyme and, finally, a side chain ring structure that determines structure solubility. They reduce LDL cholesterol levels by inhibiting the rate-limiting enzyme for cholesterol biosynthesis, HMG-CoA reductase. This is a membraneassociated protein located in the endoplasmic reticulum, and the interaction of statins with membranes is likely to influence their ability to inhibit this enzyme. Statins differ markedly in their solubility owing to the presence/absence of polar moieties on the largely hydrophobic backbones. These structural variations result in a differential distribution within the phospholipid bilayer of the cell membranes. According to their solubility, statins can be categorised as hydrophilic and lipophilic. The predominantly lipophilic statins (simvastatin, fluvastatin, lovastatin, pitavastatin, and atorvastatin) can easily pass more deeply into the membranes where they interact with the surrounding acyl chains. By contrast, hydrophilic agents (pravastatin and, to a lesser degree, rosuvastatin) remain associated with the polar surface of the membrane and require protein transporters to enter the cell to inhibit the HMGCoA reductase enzyme (6). The distinct solubility and location are also likely to be key factors involved in the metabolic differences among statins. Lipophilic statins can enter cells by passive diffusion and therefore become widely distributed in different tissues. However, the liver-specific, carrier-mediated mechanisms required for hydrophilic statin uptake could potentially reduce their ability to exert non-LDL effects at extrahepatic sites. Furthermore, the elimination of statins is also affected by solubility since lipophilic statins are metabolised by membrane-bound cytochrome P450 (CYP) enzymes, whereas hydrophilic statins are mostly eliminated without modification. The main characteristics of each statin type, including dose range, bioavailabilty, liver metabolisation and other relevant aspects are further detailed in Table 1. As an attempt to improve statin bioavailability and effectiveness, a wide variety of polymerand nanoparticle-based approaches for statin delivery have been described $(7,8)$.
Sufficient evidence of the possible beneficial or harmful effects related to statin solubility is lacking. It has been speculated that the ability of lipophilic statins to reach extrahepatic tissues could account for the more favourable cardiovascular outcomes in subjects receiving this type of lipid-lowering drug, although with a higher risk of adverse effects such as statin-associated muscle symptoms (SAMS).

The present comprehensive review aimed to describe the clinical evidence available to date regarding the possible differences in cardiovascular outcomes among statins when their solubility profile is considered, and how this may also be related to statin-related adverse effects. We hope this review will aid better understanding of statins for physicians and ultimately be useful for precise statin selection since, though they share the same mechanism of action, different chemical and pharmacological characteristics may affect their therapeutic efficacy.

\section{STATIN SOLUBILITY AND CARDIOVASCULAR OUTCOMES}

Statins inhibit cholesterol synthesis, thereby enhancing LDL clearance from the circulation. Since mevalonic acid is the precursor of numerous metabolites, HMG-CoA reductase inhibition potentially results in pleiotropic effects that may affect several tissue functions and modulate specific signal transduction pathways (Figure 2). These effects include anti-inflammatory and antioxidant activities, improvement in endothelial function, increased bioavailability of nitric oxide and delay in the progression of atherosclerotic plaques (9) (Figure 3). All these vasculoprotective effects may account for a greater magnitude of and earlier time to cardiovascular benefit than apparently explained by changes in LDL cholesterol levels alone. However, leaving aside in vitro and experimental studies, it is not possible from available clinical evidence to isolate the potential benefits of pleiotropic effects of statins from those conferred by LDL cholesterol reduction.

One of the factors to be considered when evaluating outcomes of lipid-lowering treatment with statins is their solubility. Therefore, the role of both hydrophilic and lipophilic statins regarding beneficial pleiotropic effects and thus a possible improvement in cardiovascular primary or secondary prevention needs to be analysed further.

\section{Statins and Heart Failure}

According to the 2016 European Society of Cardiology definition (10), heart failure (HF) is a complex disease caused by structural and/or functional cardiac abnormality, resulting in reduced cardiac output and/or elevated intracardiac pressures at rest or during stress. Its management is challenging owing to the clinical heterogeneity of the disease, which leads to patients responding differently to evidence-based standard therapy. Furthermore, its prevalence has suffered an exponential increase in the last decade, rendering $\mathrm{HF}$ a serious public health issue (11).

The role of statin therapy in HF remains controversial, with conflicting findings from observational studies and clinical trials 


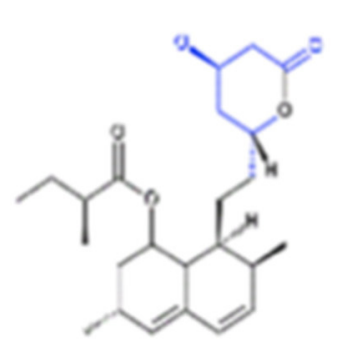

Lovastatin

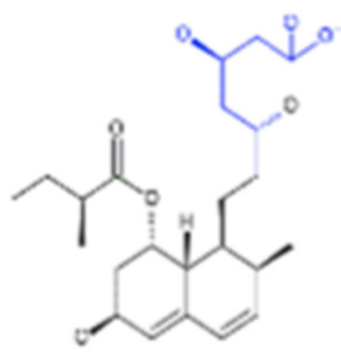

Pravastatin

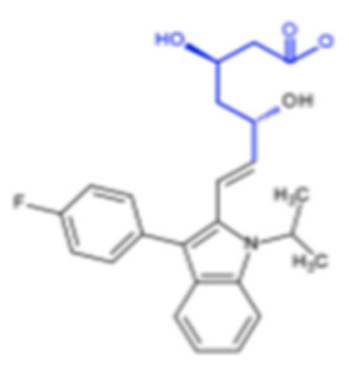

Fluvastatin

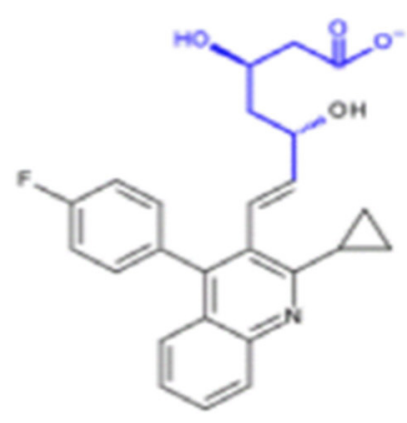

Pitavastatin

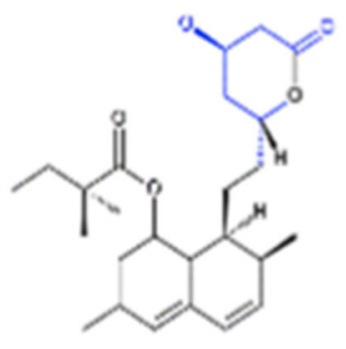

Simvastatin

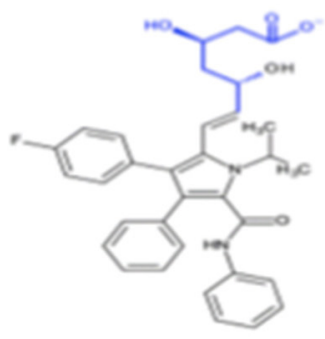

Atorvastatin

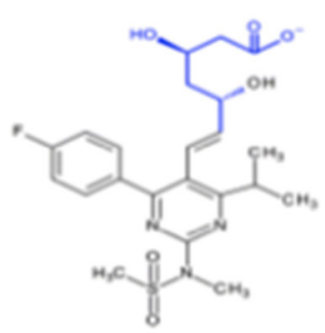

Rosuvastatin

FIGURE 1 | Chemical structure of hydrophilic and lipophilic statins.

TABLE 1 | Main characteristics of the different statins available in clinical practise.

\begin{tabular}{|c|c|c|c|c|c|c|c|}
\hline & Lovastatin & Fluvastatin & Pitavastatin & Simvastatin & Atorvastatin & Rosuvastatin & Pravastatin \\
\hline Dose range (mg/daily) & $10-80$ & $20-80$ & $1-4$ & $5-40$ & $10-80$ & $5-40$ & $20-80$ \\
\hline Bioavailability (\%) & $<5$ & 6 & $>60$ & $<5$ & 12 & 20 & 17 \\
\hline Active metabolites & Yes & No & No & Yes & Yes & Yes (minimal) & No \\
\hline Protein binding (\%) & $>95$ & 98 & 96 & 95 & $\geq 90$ & 89 & 50 \\
\hline Half-life (hours) & 2 & 4.7 & 12 & $1-2$ & 14 & 19 & $1-2$ \\
\hline Faecal excretion (\%) & 83 & 90 & 75 & 58 & 90 & 90 & 71 \\
\hline Renal excretion (\%) & 10 & $<6$ & 2 & 13 & $<2$ & 10 & 20 \\
\hline Liver metabolisation & CYP450 3A4 & CYP450 2 C9 (minor) & CYP450 2C9 & CYP450 3A4 & CYP450 3A4 & CYP450 2C9 and 2C19 & Sulphation \\
\hline Solubility & Lipophilic & Lipophilic & Lipophilic & Lipophilic & Lipophilic & Hydrophilic & Hydrophilic \\
\hline
\end{tabular}

$(12,13)$. Next, we will analyse its impact in two different clinical settings: the prevention of $\mathrm{HF}$ and the treatment of established HF.

\section{Statins and Incident HF}

Some trials (including both hydrophilic and lipohilic statins) on cardiovascular prevention reported interesting findings in the HF field. In this respect, those which compared statin vs. placebo
$(14,15)$ or more-intensive vs. less-intensive statin therapy (1619) found an HF incidence reduction in patients with stable coronary heart disease or a history of acute coronary syndrome without previous HF. Thus, efficacy in myocardial ischaemic event reduction could be involved in their benefit in incident HF prevention.

A large-scale meta-analysis of randomised primary and secondary cardiovascular prevention clinical trials with statins showed a modest reduction (10\%) in first non-fatal HF 


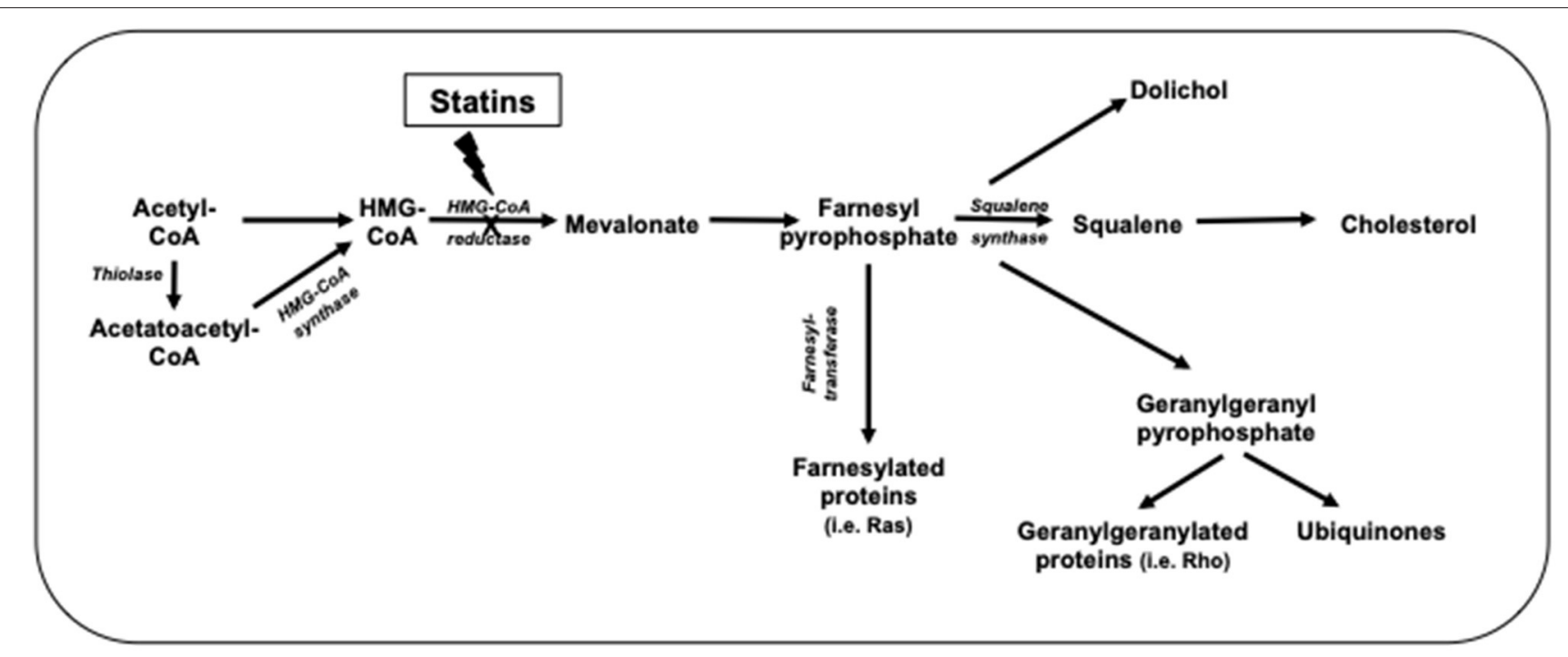

FIGURE 2 | Cholesterol biosynthetic pathway.

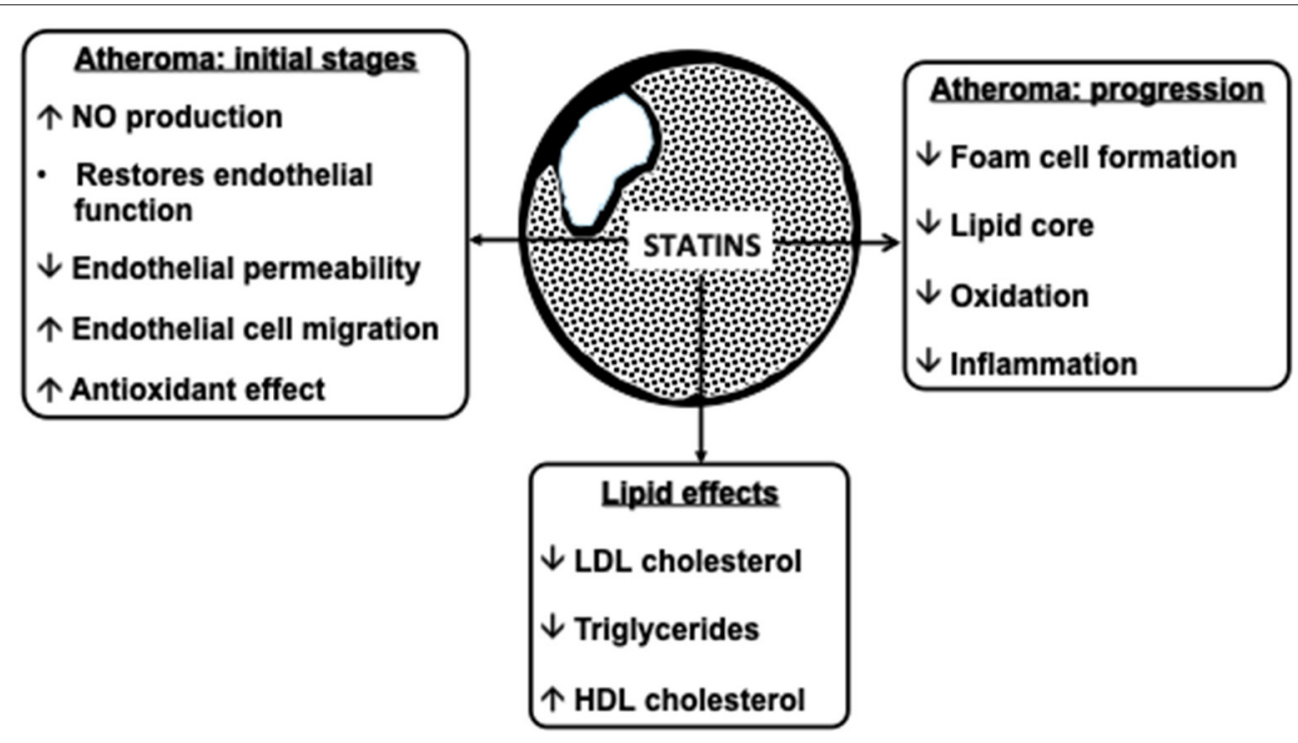

FIGURE 3 | Atheroprotective effects of statins. NO, nitric oxide; LDL, low-density lipoprotein; HDL, high-density lipoprotein.

hospitalisation with statin therapy, with no effect on HF death. However, no differences were found in risk reduction between patients who presented an incident myocardial infarction or not. Only $10-15 \%$ of non-fatal HF hospitalisations were preceded by a documented within-trial non-fatal myocardial infarction (20). Although the mechanisms by which statins reduce non-fatal HF hospitalisations are not well-established, the lack of a significant effect on HF mortality may be attributed to a non-ischaemic cause of death in HF patients.

More recently, Imran et al. (21), evaluating nearly 8 million subjects in an observational cohort study, reported a reduction in $\mathrm{HF}$ in those treated with hydrophilic compared to lipophilic statins which seemed to be driven by high-dose rather than low-dose hydrophilic statins. This was the only large cohort study using health care data designed to compare the risk of incident HF between hydrophilic and lipophilic statins.

In summary, more evidence is needed to support the use of high-intensity hydrophilic statins in the context of incident HF prevention.

\section{Statins in the Treatment of Established HF}

Data from the major lipid-lowering trials on the effects of statin therapy on prevalent HF are scant since the majority excluded patients with this syndrome $(22,23)$.

Beside small studies with atorvastatin (lipophilic) (24-26) or other statins (27) suggesting a potential benefit of these 
therapies in HF patients, two randomised controlled trials with rosuvastatin (hydrophilic), GISSI (Gruppo Italiano per lo Studio della Sopravvivenza nell'Insufficienza cardiaca) (28) and CORONA (Controlled Rosuvastatin Multinational Trial in Heart Failure) (17) were specifically conducted in an HF population. No differences in major cardiac adverse events were registered when compared to placebo; however, a reduction in HF hospitalisation was observed in CORONA. Furthermore, in a pooled analysis of both trials, Feinstein et al. (29) found a small but significant risk reduction in myocardial infarction in ischaemic HF patients treated with the hydrophilic rosuvastatin.

Data on comparative effects between lipophilic and hydrophilic statin exposure for HF-related outcomes are limited. Using an indirect comparison approach, the metaanalysis of Bonsu et al. (30), including 13 studies and 10,966 patients, reported a superiority of lipophilic statins regarding allcause mortality [odds ratio (OR) $0.50 ; 95 \%$ confidence interval (CI): $0.11-0.89 ; p=0.01$ ], cardiovascular mortality (OR: 0.61; 95\% CI: $0.25-0.97 ; p=0.009)$ and hospitalisation for worsening HF (OR 0.52; 95\% CI, 0.21-0.83; $p=0.0005$ ); however, both statin types were comparable for cardiovascular hospitalisation (OR: 0.80; 95\% CI: 0.31-1.28; $p=0.36$ ). Similarly, other studies also showed a greater risk reduction in HF events, hospitalisation and mortality (cardiovascular and all-cause) with lipophilic vs. hydrophilic statins $(20,31-34)$. It has been postulated that the greater exposure of lipophilic statins in extrahepatic tissues could account for a higher uptake by cardiac muscle (35).

The supposed superiority of lipophilic statins has also been observed when cardiac function and anti-inflammatory effects were evaluated in patients with established HF. In this respect, Bonsu et al. (36) in another meta-analysis with 19 randomised controlled trials and $\sim 6,200$ patients obtained more favourable results with lipophilic statins in improving cardiac function and reducing inflammation, with a greater rise in left ventricular ejection fraction. Lipophilic statins were also superior to hydrophilic rosuvastatin and pravastatin regarding B-type natriuretic peptide (BNP), high sensitivity C-reactive protein (hsCRP), interleukin 6 and tumour necrosis factor $\alpha$ reductions during follow-up. Takagi et al. (37) found lipophilic atorvastatin to be superior to hydrophilic rosuvastatin in improving cardiac function, with superiority of the former in inflammation attenuation and endothelial dysfunction, refuting previous reports, which supported the superiority of rosuvastatin in hsCRP level reductions.

Mortality in patients with $\mathrm{HF}$ has also been associated with cardiac sympathetic nerve activity, which in turn is one of the most important prognostic factors $(38,39)$. In this regard, previous evidence once again showed the superiority of lipophilic atorvastatin vs. hydrophilic rosuvastatin in sympathetic nerve activity reduction in patients with HF (40). In that face-to face trial (40), $5 \mathrm{mg}$ of lipophilic atorvastatin was compared to $2.5 \mathrm{mg}$ of hydrophilic rosuvastatin in patients with dilated cardiomyopathy. As to lipid profile outcome, total and LDL cholesterol reductions were similar between groups. However, the atorvastatin group presented an increased heart/mediastinum ratio (which is known marker of an increased noradrenaline uptake), improved left ventricular ejection fraction, and greater reduction in BNP levels. Hence, beyond improving lipid profile, these findings emphasise the role of statins on inflammation response (41). Moreover, preclinical evidence suggests that the pleiotropic effects of statins may improve survival rates in ischaemic and non-ischaemic HF subjects by regulating the autonomic nervous system through angiotensin II and nitric oxide modulation (42). However, preliminary human studies reported mixed results. Indeed, Horwich al. (43) found that short-term statin treatment failed to result in a significant reduction in autonomic nervous system activation in HF patients. In contrast, a large meta-analysis of 13 randomised trials reported that lipophilic statins significantly lowered all-cause mortality, hospitalisation for worsening HF and LDL cholesterol, regardless of age, baseline left ventricular ejection fraction and cause of HF (32).

Other studies evaluated possible explanations for more favourable results with hydrophilic statins. In this respect, some studies reported that fat-soluble statins induced a pro-apoptotic state in human adult cardiac myocytes in vitro (44). Similarly, it has been speculated that lipophilic statins might inhibit CoQ10 biosynthesis, leading to disturbances in cardiac energy metabolism (45). A previous study showed that switching from lipophilic simvastatin to the hydrophilic pravastatin led to an increase in plasma adiponectinaemia with no change in LDL cholesterol concentrations (46).

A recent study comparing the effects of atorvastatin vs. rosuvastatin on left ventricular function, inflammatory and fibrosis biomarkers in patients with chronic HF, published by El Said et al. (47) suggested that the impact of lipophilic atorvastatin was greater than that of hydrophilic rosuvastatin in HF patients with regards to the improvement in left ventricular ejection fraction and soluble suppression of tumorigenicity reduction, a novel fibrosis marker.

Finally, we believe the results of a post-hoc analysis of the CORONA trial are worth mentioning (48). Plasma galectin 3 (a mediator of fibrogenesis) levels were evaluated in subjects with established systolic HF included in the CORONA trial that were randomised to $10 \mathrm{mg}$ or rosuvastatin daily or placebo. It was observed that among patients with below the median plasma concentrations of galectin $3(\leq 19 \mathrm{ng} / \mathrm{ml})$, those receiving rousvastatin treatment presented a lower primary event rate (defined as cardiovascular death, myocardial infarction or stroke), lower mortality rate and lower rate of all-cause mortality or HF hospitalisation. However, these benefits were not observed in patients with higher galectin 3 levels. Thus, these results may highlight the hypothetical role of galectin 3 to identify subjects with HF or chronic left ventricular systolic dysfuncion that might benefit of statins treatment, although further studies are required.

Thus, to date, the rationale for proving the superiority of one statin type over the other remains unclear. Although some studies have described possible pathophysiological mechanisms that could favour hydrophilic or lipophilic statins regarding HF outcomes, these have not been further confirmed. Future trials with larger sample size and longer follow-up are essential to ascertain whether real differences exist among statins owing to their solubility profile, and hence play a role when the optimal lipid-lowering therapy is decided upon for each patient 
in clinical practise. Meanwhile, statin use as HF therapy is not recommended.

\section{Statins and Coronary Heart Disease}

As in HF outcomes, previous studies have also yielded conflicting results concerning the possible benefits of different statin types owing to their solubility in primary of CHD prevention and in established cardiovascular disease $(49,50)$.

\section{Primary CHD Prevention}

The valuable role of statins in primary CHD prevention has been unequivocally confirmed in previous reports. Data from the Cholesterol Treatment Trialists' (CTT) Collaborators of statin treatment in people at low cardiovascular risk demonstrated a 9\% reduction [relative risk (RR): $0.91,95 \%$ CI: $0.85-0.97$ ] in allcause mortality and $25 \%$ (RR: $0.75,95 \%$ CI: $0.70-0.80$ ) in major vascular events per $1.0 \mathrm{mmol} / \mathrm{L}$ reduction in LDL cholesterol, even among low-risk patients (4). Furthermore, a 2013 Cochrane analysis corroborated these findings with a $14 \%$ reduction (OR: $0.86,95 \%$ CI: $0.79-0.94$ ) in all-cause mortality and $25 \%$ (RR: 0.75 , 95\% CI: 0.70-0.81) in cardiovascular events (51).

Whether the solubility profile of each statin type could account for this favourable cardiovascular benefit remains open to debate. In this respect, the previously mentioned CTT meta-analysis (4) included some studies that compared various statin types; however, the differences observed in cardiovascular outcomes were attributed to statin potency (intensive vs. less intensive), and no mention was made of the solubility profile resulting in more favourable outcomes.

\section{Secondary CHD Prevention}

The possible differences between hydrophilic and lipophilic statins have mainly been evaluated regarding secondary cardiovascular prevention in patients with acute coronary syndrome and stable CHD (Table 2) (52-59).

Back in 2004, the PROVE IT-TIMI 22 trial (52) compared a standard therapy of $40 \mathrm{mg}$ pravastatin daily with an intensive therapy of $80 \mathrm{mg}$ atorvastatin daily, observing that an intensive lipid-lowering statin strategy provided greater protection against death or major adverse cardiovascular events (MACE) than a standard regimen. Similarly to the results from observational studies, the greater LDL cholesterol reduction with lipophilic atorvastatin compared to hydrophilic pravastatin could probably account for the more favourable cardiovascular results observed in subjects receiving the former, although whether the solubility profile of each statin could also play a role in these observed differences could also be speculated.

Kim et al. (60) found a higher composite of MACE in the hydrophilic statin group at 1 and 6 months ( 1 month: 10.0 vs. $4.4 \% ; p=0.001 ; 6$ months: 19.9 vs. $14.2 \% ; p=0.022$ ), whereas no significant difference in MACE was observed at 1 year of followup ( 21.5 vs. $17.9 \% ; p=0.172)$. Both statin arms showed similar efficacy in the lipid profile and the use of a hydrophilic statin did not predict 1-year MACE, all-cause death, acute myocardial infarction or re-percutaneous coronary intervention.

To shed light on this matter, further trials such as that reported by Sakamoto et al. (55) in 2007 directly compared the lipophilics atorvastatin, fluvastatin, pitavastatin and simvastatin to hydrophilic pravastatin. Although LDL cholesterol was reduced more potently in the lipophilic than the hydrophilic groups ( -34 vs. $-19 \% ; p=0.0069$ ), acute coronary syndromes tended to occur less frequently (3.6 vs. 9.9\%; $p=0.0530$ ) and the incidence of new a Q-wave appearance on electrocardiogram was significantly lower (75 vs. $89 \% ; p=0.0056$ ) with hydrophilic pravastatin than with lipophilic statins. The CENTAURUS trial (56) also obtained more favourable results with hydrophilic statins, with rosuvastatin $20 \mathrm{mg}$ being more effective than lipophilic atorvastatin $80 \mathrm{mg}$ in reducing the apoB/apoA-1 ratio at 1 month ( -44.4 vs. $-42.9 \%, p=0.02)$, although these results were not further confirmed with a longer follow-up. Finally, Izawa et al. (59) obtained more favourable results with hydrophilic pravastatin (MACE $30.4 \%$ after pravastatin vs. $31.4 \%$ in the atorvastatin group), although greater reductions in total and LDL cholesterol were achieved in the atorvastatin group ( $p$ $<0.001$ for each).

On the other hand, the findings of Bytyçi et al. (61) between hydrophilic and lipophilic statins were comparable in terms of risk reduction for MACE (RR: 0.969; 95\% CI: $0.835-1.125 ; p=$ 0.682 ), myocardial ischaemia (RR: 0.880; 95\% CI: 0.731-1.058; $p$ $=0.174$ ), cardiovascular death (RR: 0.757; 95\% CI: 0.486-1.180; $p=0.219$ ) and all-cause mortality (RR: 0.797 ; $95 \%$ CI: $0.590-$ $1.075 ; p=0.137)$. However, the cardiovascular hospitalisation rate was lower (RR: 0.789; 95\% CI: $0.643-0.969 ; p=0.024$ ) and alanine aminotransferase (ALT) elevation higher (RR: 2.689; 95\% CI: $1.841-3.954 ; p<0.001)$ in lipophilic- than in hydrophilictreated patients.

With regard to coronary atherosclerosis progression/regression studies, the REVERSAL trial (53) assessed the effect of different statin regimens designed to produce intensive or moderate lipid lowering of the coronary artery atheroma burden and progression. Six hundred and fifty-four patients were randomly assigned to receive a moderate lipid-lowering regimen consisting of $40 \mathrm{mg}$ pravastatin or an intensive lipid-lowering regimen with $80 \mathrm{mg}$ atorvastatin. They observed that the percentage change in atheroma volume revealed a significantly lower progression rate in the lipophilic atorvastatin group compared with the hydrophilic pravastatin group ( $p=0.02)$. However, as in the CTT meta-analysis (4), this could probably be explained by the fact that the LDL cholesterol reduction was greater in the atorvastatin than the pravastatin groups ( $p<0.001$ ), and hence the solubility profile of each statin and the possible superiority of lipophilic statins could play a secondary role in the observed differences.

Moving forward, it must be acknowledged that the previously mentioned studies focused mainly on acute coronary syndrome. Here, the possible beneficial effects of one statin type or the other (hydrophilic vs. lipophilic) may probably depend more on their pleiotropic effects since the impact of lipidlowering therapy in LDL cholesterol reduction has not yet been attained. However, when the focus is on chronic ischaemic heart disease, the beneficial effects of LDL cholesterol reduction may be present to the same degree as the pleiotropic changes. In this respect, Deedwania et al. (54) evaluated 893 outpatients with chronic stable ischaemic heart disease 
TABLE 2 | Trials comparing hydrophilic and lipophilic statins and coronary artery disease.

\begin{tabular}{|c|c|c|c|c|c|}
\hline Study (reference) & $\begin{array}{l}\text { Study } \\
\text { design }\end{array}$ & $\begin{array}{l}\text { Follow-up } \\
\text { (months) }\end{array}$ & Trial comparison & $\begin{array}{l}\text { Primary } \\
\text { endpoints }\end{array}$ & Main results \\
\hline $\begin{array}{l}\text { PROVE IT-TIMI } 22 \\
\text { (52) }\end{array}$ & $\begin{array}{l}\mathrm{RCT} \\
\text { double-blind }\end{array}$ & 24 & $\begin{array}{l}\text { Pravastatin } 40 \mathrm{mg} \\
\text { vs. atorvastatin } \\
80 \mathrm{mg}\end{array}$ & MACE & $\begin{array}{l}\text { MACE } 26.3 \% \text { after pravastatin and } 22.4 \% \text { after } \\
\text { atorvastatin; } p=0.005\end{array}$ \\
\hline REVERSAL (53) & $\begin{array}{l}\mathrm{RCT} \\
\text { double-blind }\end{array}$ & 18 & $\begin{array}{l}\text { Atorvastatin } 80 \mathrm{mg} \\
\text { vs. pravastatin } \\
40 \mathrm{mg}\end{array}$ & $\begin{array}{l}\text { Percentage } \\
\text { change in total } \\
\text { atheroma volume }\end{array}$ & $\begin{array}{l}\text { Significantly lower progression rate of atheroma volume } \\
\text { in atorvastatin group }(p=0.02) \text {. Coronary } \\
\text { atherosclerosis progression in pravastatin group }(2.7 \% \text {; } \\
95 \% \mathrm{Cl}, 0.2-4.7 \% ; p=0.001) \text { compared with baseline. } \\
\text { No progression in atorvastatin arm }(-0.4 \% ; \mathrm{Cl}-2.4 \text { to } \\
1.5 \% ; p=0.98) \text { compared with baseline. }\end{array}$ \\
\hline SAGE (54) & $\begin{array}{l}\text { RCT, } \\
\text { double-blind }\end{array}$ & 12 & $\begin{array}{l}\text { Atorvastatin } 80 \mathrm{mg} \\
\text { vs. pravastatin } \\
40 \mathrm{mg}\end{array}$ & $\begin{array}{l}\text { Total duration of } \\
\text { ischaemia on } 48 \mathrm{~h} \\
\text { holter- monitor }\end{array}$ & $\begin{array}{l}\text { Absolute change from baseline in total duration of } \\
\text { ischaemia at month } 12 \text { significantly reduced in both } \\
\text { groups ( } p<0.001 \text { for each treatment group) with no } \\
\text { significant difference between treatment groups. } \\
\text { Atorvastatin greater LDL cholesterol reductions than } \\
\text { pravastatin, trend towards fewer MACE (hazard ratio, } \\
0.71 ; 95 \% \mathrm{Cl}, 0.46-1.09 ; p=0.114 \text { ), and a significantly } \\
\text { greater reduction in all-cause death (hazard ratio, } 0.33 \text {; } \\
95 \% \mathrm{Cl}, 0.13-0.83 ; p=0.014 \text { ). }\end{array}$ \\
\hline $\begin{array}{l}\text { MUSASHI-AMI } \\
\text { (55) }\end{array}$ & $\begin{array}{l}\text { RCT, } \\
\text { double-blind }\end{array}$ & 24 & $\begin{array}{l}\text { Lipophilic } \\
\text { (atorvastatin, } \\
\text { simvastatin, } \\
\text { pitavastatin, } \\
\text { fluvastatin) vs. } \\
\text { hydrophilic } \\
\text { (pravastatin) }\end{array}$ & $\begin{array}{l}\text { CV death, } \\
\text { non-fatal MI, } \\
\text { recurrent acute } \\
\text { myocardial } \\
\text { ischaemia }\end{array}$ & $\begin{array}{l}\text { Although LDL cholesterol was reduced more potently in } \\
\text { the lipophilic group ( }-34 \text { vs. }-19 \% ; p=0.0069) \text {, ACS } \\
\text { tended to occur less frequently ( } 3.6 \text { vs. 9.9\%; } p= \\
0.0530 \text { ) and the incidence of new Q-wave in ECG was } \\
\text { significantly lower ( } 75 \text { vs. } 89 \% ; p=0.0056 \text { ) in the } \\
\text { hydrophilic group. }\end{array}$ \\
\hline CENTAURUS (56) & $\begin{array}{l}\text { RCT, } \\
\text { double-blind } \\
\text { parallel group } \\
\text { trial }\end{array}$ & 3 & $\begin{array}{l}\text { Atorvastatin } 80 \mathrm{mg} \\
\text { vs. rosuvastatin } \\
20 \mathrm{mg}\end{array}$ & $\begin{array}{l}\text { Percentage } \\
\text { change in } \\
\text { ApoB/ApoA-1 } \\
\text { ratio }\end{array}$ & $\begin{array}{l}\text { Rosuvastatin } 20 \mathrm{mg} \text { was more effective than atorvastatin } \\
80 \mathrm{mg} \text { in decreasing apoB/apoA-1 ratio at } 1 \text { month } \\
(-44.4 \text { vs. }-42.9 \%, p=0.02 \text { ), but not at } 3 \text { months } \\
\text { (both }-44.4 \%, p=0.87 \text { ). }\end{array}$ \\
\hline LUNAR (57) & $\begin{array}{l}\text { RCT, } \\
\text { open-label, } \\
\text { parallel group } \\
\text { trial }\end{array}$ & 3 & $\begin{array}{l}\text { Atorvastatin } 80 \mathrm{mg} \\
\text { vs. rosuvastatin } \\
20-40 \mathrm{mg}\end{array}$ & $\begin{array}{l}\text { Change in LDL } \\
\text { cholesterol }\end{array}$ & $\begin{array}{l}\text { Rosuvastatin } 40 \text { mg efficacy in lowering LDL cholesterol } \\
\text { levels was significantly greater vs. atorvastatin } 80 \mathrm{mg} \\
\text { ( } 46.8 \text { vs. } 42.7 \% \text { decrease, } p=0.02) \text {. Comparable } \\
\text { results for rosuvastatin } 20 \text { and atorvastatin } 80 \mathrm{mg} \text {. } \\
\text { Increase in HDL cholesterol was significantly greater with } \\
\text { rosuvastatin } 40(11.9 \%, p<0.001) \text { and } 20 \mathrm{mg}(9.7 \%, p \\
<0.01 \text { ) than with atorvastatin } 80 \mathrm{mg}(5.6 \%) \text {. }\end{array}$ \\
\hline The ROMA II (58) & $\begin{array}{l}\mathrm{RCT} \\
\text { double-blind }\end{array}$ & 12 & $\begin{array}{l}\text { Atorvastatin } 80 \mathrm{mg} \\
\text { vs. rosuvastatin } \\
40 \mathrm{mg} \text { vs. controls } \\
\text { on chronic statin } \\
\text { therapy without } \\
\text { reloading }\end{array}$ & $\begin{array}{l}\text { Incidence of peri- } \\
\text { procedural MI, } \\
\text { MACE }\end{array}$ & $\begin{array}{l}12 \text { and } 24 \text {-h post-PCI CK-MB elevation }>3 \times \text { occurred } \\
\text { more frequently in control than in the rosuvastatin and } \\
\text { atorvastatin groups (at } 24-\mathrm{h}: 25.0 \text { vs. } 7.1 ; p=0.003 \text { and } \\
25.0 \text { vs. } 6.1 ; p=0.001 \text { ). } \\
\text { At } 30 \text {-day, } 6 \text { - and } 12 \text {-month follow-up, the incidence of } \\
\text { MACE was higher in the control group than in the } \\
\text { rosuvastatin or atorvastatin groups (at } 12 \text {-month: } 41.0 \\
\text { vs. } 11.4 \text { vs. } 12.0 \% ; p=0.001 \text { ). }\end{array}$ \\
\hline ALPS-AMI (59) & $\begin{array}{l}\text { RCT, open } \\
\text {-label, } \\
\text { blinded- } \\
\text { endpoint }\end{array}$ & 24 & $\begin{array}{l}\text { Atorvastatin } \\
10-20 \mathrm{mg} \text { vs. } \\
\text { pravastatin } \\
10-20 \mathrm{mg}\end{array}$ & $\begin{array}{l}\text { All-cause death, } \\
\text { CV death, MI, } \\
\text { stroke, } \\
\text { revascularisation, } \\
\text { hospitalisation }\end{array}$ & $\begin{array}{l}\text { Primary endpoint occurred in } 77(30.4 \%) \text { and in } 80 \\
\text { patients }(31.4 \%) \text { in the pravastatin and atorvastatin } \\
\text { groups, respectively (hazard ratio, } 1.181 ; 95 \% \mathrm{Cl} \text { : } \\
0.862-1.619 ; p=0.299) \text {, whereas greater reductions in } \\
\text { total and LDL cholesterol were achieved in the } \\
\text { atorvastatin group ( } p<0.001 \text { for each). }\end{array}$ \\
\hline
\end{tabular}

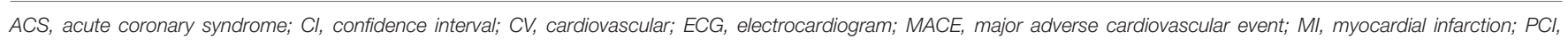
percutaneous coronary intervention; RCT, randomised controlled trial.

randomised to atorvastatin $80 \mathrm{mg}$ (lipophilic) or pravastatin $40 \mathrm{mg}$ (hydrophilic) and followed for 12 months. The primary efficacy parameter (absolute change from baseline in total ischaemia duration at month 12) was significantly reduced in both groups at months 3 and 12 ( $p<0.001$ for each treatment group) with no significant difference between treatment groups. However, atorvastatin-treated patients had greater LDL cholesterol reductions than pravastatin-treated patients, a trend towards fewer MACE (hazard ratio: 0.71; 95\% CI: $0.46,1.09 ; p=0.114$ ) and a significantly greater reduction in all-cause death (hazard ratio: 0.33 ; 95\% CI: $0.13,0.83 ; p=$ $0.014)$. Hence, as previously mentioned, the probable superiority 
of lipophilic atorvastatin could once again be explained by its greater potency in lowering LDL cholesterol concentrations.

Finally, the possible pleiotropic effects that may account for all these observed results include decreased adenosine triphosphate (ATP) production with lipophilic statins and enhanced myocardial stunning after ischaemia and reperfusion (62), with direct beneficial effects on cardiovascular outcomes. Moreover, it has been further observed that lipophilic simvastatin enhances myocardial stunning compared with controls and hydrophilic pravastatin (45). However, both types of statins, apart from their lipid-lowering effect, increase nitric oxide production and release (63), thus protecting the myocardium against ischaemia-reperfusion injury, and reduce infarct size $(64,65)$.

Nevertheless, while some studies, particularly randomised controlled trials, detected superiority of hydrophilic statins regarding to secondary CHD prevention, others reported greater LDL cholesterol reductions with lipophilic statins, which could also account for the more favourable cardiovascular outcomes. As for HF outcomes, we believe future randomised trials with longer follow-up are mandatory to confirm the possible superiority of one statin type over the other taking into account their solubility profile, and regardless of their intensity in lowering LDL cholesterol levels.

\section{Statins and Atrial Fibrillation-Related Stroke}

The possible differences between statin types and the risk of atrial fibrillation related stroke has also been evaluated. In this sense, a meta-analysis (66) including a total of 8 studies evaluated the clinical outcomes both for pre- and poststroke statins. They observed that post-stroke statin therapy reduced total mortality regardless of statin intensity. However, no differences were observed regarding statin treatment and a reduction in the risk of recurrent ischaemic stroke. As to pre-stroke statins, initiating lipid-lowering treatment before the event was associated with a lower risk of poor short-tem functional outcomes. Another recent meta-analysis in atrial fibrillation patients conformed a reduction in all-cause and cardiovascular mortality rates (67). Despite these favourable results, possible differences between statins about their solubility profile were not assessed; hence future studies are needed in this field to reach more solid conclusions that can be useful in clinical practise.

\section{STATIN SOLUBILITY AND ADVERSE EFFECTS}

Although the different statin types have possible beneficial effects depending on their solubility profile, safety cannot be ignored. It has been argued that the benefits of lipophilic statins may transcend into diverse adverse reactions owing to their easy penetration into extrahepatic tissues. However, solid evidence is still lacking in this field $(17,28,68)$. On the other hand, the hepatoselectivity of hydrophilic statins could also translate into specific organ damage, although their lower tissue absorption and lower dependence on the cytochrome P450 enzyme compared to lipophilic statins could explain a drop in the number of side effects in subjects treated with these types of statin (69).

Firstly, the prevalence of SAMS differs between statin classes. Lipophilic statins such as simvastatin, atorvastatin, fluvastatin, pitavastatin and lovastatin, owing to their well-known ability to non-selectively diffuse into extrahepatic tissues, such as skeletal muscle, carry a higher risk of SAMS. In contrast, hydrophilic statins have less muscle penetration and therefore lower risk (70). However, based on a recent observational cohort study, equipotent hydrophilic statins were not better tolerated compared to lipophilic statins (71). It must also be considered that, beside the statin type, the risk of SAMS also depends on other factors such as the concomitant use of drugs metabolised by the same hepatic cytochrome P450 isoforms (72). Other risk factors for SAMS to be consideret include family history of muscular symptoms with lipid-lowering therapy, untreated hypothyroidism, female sex, older age and low body mass index, among others (73).

Secondly, the presence of new-onset diabetes mellitus with statin therapy should also be mentioned. This seems to be more frequent in patients with pre-existing risk factors, including metabolic syndrome traits (74). It has been observed for both hydrophilic and lipophilic statins and appears to occur more frequently in older patients and those on high-dose statin therapy; however, a relationship with statin solubility has not been described (70).

As for neurological disorders, it has been hypothesised that lipophilic statins could induce a higher risk given their increased ability to cross the blood-brain barrier (75); however, these findings have not been confirmed in further studies. Furthermore, it should be noted that these effects may not be specific to statin type per se but rather result from changes in cholesterol concentrations.

Finally, controversy persists regarding the effects of statins on renal function. Except for hydrophilic pravastatin and rosuvastatin, the remaining statins are mainly metabolised by the liver and minimally cleared by the kidney. Mild transient proteinuria has previously been observed in some patients when receiving high-dose statin treatment; however, this has not been firmly associated with impaired renal function (76).

\section{CONCLUSIONS}

The classification of drugs as hydrophilic or lipophilic depends on their ability to dissolve in lipid media or in water. The predominantly lipophilic statins can easily enter cells and interact with cell membranes, whereas hydrophilic statins present greater hepatoselectivity.

Conflicting results have been observed on the superiority of hydrophilic or lipophilic statins regarding cardiovascular outcomes, including $\mathrm{HF}$ and $\mathrm{CHD}$, both from primary and secondary prevention. In this respect, the possible superiority of lipophilic statins seen in some studies could be explained by 
a greater LDL cholesterol reduction with this statin type, with the solubility profile playing a secondary role in the favourable cardiovascular outcomes observed.

Finally, the non-selective diffusion of lipophilic statins into extrahepatic tissues could account for an increase in SAMS, albeit without differences between hydrophilic and lipophilic statins with respect to other adverse effects. Thus, we believe future studies are essential in this field for the solubility profile of statins to be taken into account when deciding on the optimal lipid-lowering therapy for each patient in daily clinical practise.

\section{REFERENCES}

1. Buxton ILO, Benet LZ. Pharmacokinetics: the dynamics of drug absorption, distribution, metabolism, and elimination. In: Brunton LL, Chabner BA, Knollman BC, editors. Goodman and Gilman's the Pharmacological Basis of Therapeutics. 12th ed. New York, NY: McGraw-Hill (2011) p. 17-39.

2. Baigent C, Keech A, Kearney PM, Blackwell L, Buck G, Pollicino C, et al. Efficacy and safety of cholesterol-lowering treatment: prospective metaanalysis of data from 90,056 participants in 14 randomised trials of statins. Lancet. (2005) 366:1267-78. doi: 10.1016/S0140-6736(05)67394-1

3. Cholesterol Treatment Trialists' (CTT) Collaboration, Baigent C, Blackwell L, Emberson J, Holland LE, Reith C, et al. Efficacy and safety of more intensive lowering of LDL cholesterol: a meta-analysis of data from 170,000 participants in 26 randomised trials. Lancet. (2010) 376:167081. doi: 10.1016/S0140-6736(10)61350-5

4. Cholesterol Treatment Trialists' (CTT) Collaborators, Mihaylova B, Emberson J, Blackwell L, Keech A, Simes J, et al. The effects of lowering LDL cholesterol with statin therapy in people at low risk of vascular disease: meta-analysis of individual data from 27 randomised trials. Lancet. (2012) 380:581-90. doi: 10.1016/S0140-6736(12)60367-5

5. Cholesterol Treatment Trialists' Collaboration. Efficacy and safety of statin therapy in older people: a meta-analysis of individual participant data from 28 randomised controlled trials. Lancet. (2019) 393:40715. doi: 10.1016/S0140-6736(18)31942-1

6. Egom EE, Hafeez H. Biochemistry of statins. Adv Clin Chem. (2016) 73:12768. doi: 10.1016/bs.acc.2015.10.005

7. Groner J, Goepferich A, Breunig M. Atherosclerosis: conventional intake of cardiovascular drugs versus delivery using nanotechnology - a new chance for causative therapy? J Control Release. (2021) 333:536-59. doi: 10.1016/j.jconrel.2021.03.034

8. Nenna A, Nappi F, Larobina D, Verghi E, Chello M, Ambrosio L. Polymers and nanoparticles for statin delivery: current use and future perspectives in cardiovascular disease. Polymers. (2021) 13:711. doi: 10.3390/polym13050711

9. Wang C-Y, Liu P-Y, Liao JK. Pleiotropic effects of statin therapy. Trends Mol Med. (2008) 14:37-44. doi: 10.1016/j.molmed.2007.11.004

10. Ponikowski P, Voors AA, Anker SD, Bueno H, Cleland JGF, Coats AJS, et al. 2016 ESC Guidelines for the diagnosis treatment of acute chronic heart failure: The Task Force for the diagnosis treatment of acute chronic heart failure of the European Society of Cardiology (ESC) developed with the special contribution of the Heart Failure Association (HFA) of the ESC. Eur Heart J. (2016) 37:2129-200. doi: 10.1093/eurheartj/ehw128

11. Ponikowski P, Anker SD, AlHabib KF, Cowie MR, Force TL, Hu S, et al. Heart failure: preventing disease and death worldwide. ESC Heart Fail. (2014) 1:4-25. doi: 10.1002/ehf2.12005

12. Javaheri A, Rader DJ, Javaheri S. Statin therapy in heart failure. Is it time for a second look? Hypertension. (2014) 63:909-10. doi: 10.1161/HYPERTENSIONAHA.113.02703

13. Chillarón JJ, Benaiges D, Climent E, Flores-Le Roux JA, PedroBotet J. Statins and heart failure. J Cardiol Ther. (2015) 2:405-9. doi: 10.17554/j.issn.2309-6861.2015.02.86

14. The Long-Term Intervention with Pravastatin in Ischemic Disease (LIPID) Study Group. Prevention of cardiovascular events and death with pravastatin in patients with coronary heart disease and a broad range of initial cholesterol

\section{AUTHOR CONTRIBUTIONS}

The first version of the manuscript was written by EC, and revised and approved by DB and JP-B. All authors contributed to the article and approved the submitted version.

\section{ACKNOWLEDGMENTS}

The authors thank Miss Christine O'Hara for review of the English version of the manuscript.

levels. The Long-Term Intervention with Pravastatin in Ischaemic Disease (LIPID) Study Group. N Engl J Med. (1998) 339:1349-57.

15. Kjekshus J, Pedersen TR, Olsson AG, Faergeman O, Pyorala K. The effects of simvastatin on the incidence of heart failure in patients with coronary heart disease. J Card Fail. (1997) 3:249-54. doi: 10.1016/S1071-9164(97)90022-1

16. Khush KK, Waters DD, Bittner V, Deedwania PC, Kastelein JJ, Lewis SJ, et al. Effect of high-dose atorvastatin on hospitalizations for heart failure: subgroup analysis of the treating to new targets (TNT) study. Circulation. (2007) 115:576-83. doi: 10.1161/CIRCULATIONAHA.106.625574

17. Kjekshus J, Apetrei E, Barrios V, Böhm M, Cleland JG, Cornel JH, et al. Rosuvastatin in older patients with systolic heart failure. N Engl J Med. (2007) 357:2248-61. doi: 10.1056/NEJMoa0706201

18. Sacks FM, Pfeffer MA, Moye LA, Rouleau JL, Rutherford JD, Cole TG, et al. The effect of pravastatin on coronary events after myocardial infarction in patients with average cholesterol levels. Cholesterol and Recurrent Events Trial investigators. N Engl J Med. (1996) 335:10019. doi: 10.1056/NEJM199610033351401

19. Scirica BM, Morrow DA, Cannon CP, Ray KK, Sabatine MS, Jarolim P, et al. Intensive statin therapy and the risk of hospitalization for heart failure after an acute coronary syndrome in the PROVE IT-TIMI 22 study. J Am Coll Cardiol. (2006) 47:2326-31. doi: 10.1016/j.jacc.2006.03.034

20. Preiss D, Campbell RT, Murray HM, Ford I, Packard CJ, Sattar N, et al. The effect of statin therapy on HF events: a collaborative meta-analysis of unpublished data from major randomized trials. Eur Heart J. (2015) 36:153646. doi: 10.1093/eurheartj/ehv072

21. Imran T, Wong A, Schneeweiss S, Desai RJ. Statin lipophilicity and the risk of incident heart failure. Cardiology. (2020) 145:375-83. doi: 10.1159/000506003

22. Krum H, McMurray JJ. Statins and chronic heart failure: do we need a large-scale outcome trial? J Am Coll Cardiol. (2002) 39:156773. doi: 10.1016/S0735-1097(02)01827-2

23. Kjekshus J, Dunselman P, Blideskog M, Eskilson C, Hjalmarson Å, McMurray JV, et al. A statin in the treatment of heart failure? Controlled rosuvastatin multinational study in heart failure (CORONA): study design and baseline characteristics. Eur J Heart Fail. (2005) 7:105969. doi: 10.1016/j.ejheart.2005.09.005

24. Wojnicz R, Wilczek K, Nowalany-Kozielska E, Szyguła-Jurkiewicz B, Nowak J, Poloński L, et al. Usefulness of atorvastatin in patients with heart failure due to inflammatory dilated cardiomyopathy and elevated cholesterol levels. Am J Cardiol. (2006) 97:899-904. doi: 10.1016/j.amjcard.2005.09.142

25. Vrtovec B, Okrajsek R, Golicnik A, Ferjan M, Starc V, Schlegel TT, et al. Atorvastatin therapy may reduce the incidence of sudden cardiac death in patients with advanced chronic heart failure. J Card Fail. (2008) 14:1404. doi: 10.1016/j.cardfail.2007.10.013

26. Xie RQ, Cui W, Liu F, Yang C, Pei WN, Lu JC. Statin therapy shortens QTc, QTcd, and improves cardiac function in patients with chronic heart failure. Int J Cardiol. (2010) 140:255-7. doi: 10.1016/j.ijcard.2008.11.030

27. Mozaffarian D, Nye R, Levy WC. Statin therapy is associated with lower mortality among patients with severe heart failure. Am J Cardiol. (2004) 93:1124-9. doi: 10.1016/j.amjcard.2004.01.039

28. Tavazzi L, Maggioni AP, Marchioli R, Barlera S, Franzosi MG, Latini R, et al. Effect of rosuvastatin in patients with chronic HF (the GISSI-HF trial): a randomised, double-blind, placebo-controlled trial. Lancet. (2008) 372:12319. doi: 10.1016/S0140-6736(08)61240-4 
29. Feinstein MJ, Jhund P, Kang J, Ning H, Maggioni A, Wikstrand J, et al. Do statins reduce the risk of myocardial infarction in patients with heart failure? A pooled individual-level reanalysis of CORONA and GISSI-HF. Eur J Heart Fail. (2015) 17:434-41. doi: 10.1002/ejhf.247

30. Bonsu KO, Reidpath DD, Kadirvelu A. Lipophilic statin versus rosuvastatin (hydrophilic) treatment for heart failure: a meta-analysis and adjusted indirect comparison of randomised trials. Cardiovasc Drugs Ther. (2016) 30:17788. doi: 10.1007/s10557-015-6636-z

31. Lipinski MJ, Cauthen CA, Biondi-Zoccai GG, Abbate A, Vrtovec B, Khan $\mathrm{BV}$, et al. Meta-analysis of randomized controlled trials of statins versus placebo in patients with heart failure. Am J Cardiol. (2009) 104:170816. doi: 10.1016/j.amjcard.2009.07.055

32. Liu G, Zheng XX, Xu YL, Lu J, Hui RT, Huang XH. Effects of lipophilic statins for heart failure: a meta-analysis of 13 randomised controlled trials. Heart Lung Circ. (2014) 23:970-7. doi: 10.1016/j.hlc.2014. 05.005

33. Zhang L, Zhang S, Jiang H, Sun A, Wang Y, Zou Y, et al. Effects of statin therapy on inflammatory markers in chronic heart failure: a metaanalysis of randomized controlled trials. Arch Med Res. (2010) 41:46471. doi: 10.1016/j.arcmed.2010.08.009

34. Zhang L, Zhang S, Jiang H, Sun A, Zou Y, Ge J. Effects of statin treatment on cardiac function in patients with chronic heart failure: a meta-analysis of randomized controlled trials. Clin Cardiol. (2011) 34:11723. doi: $10.1002 / \mathrm{clc} .20821$

35. Schachter M. Chemical, pharmacokinetic and pharmacodynamic properties of statins: an update. Fundam Clin Pharmacol. (2005) 19:117-25. doi: 10.1111/j.1472-8206.2004.00299.x

36. Bonsu KO, Reidpath DD, Kadirvelu A. Effects of statin treatment on inflammation and cardiac function in heart failure: an adjusted indirect comparison meta-analysis of randomized trials. Cardiovasc Ther. (2015) 33:338-46. doi: 10.1111/1755-5922.12150

37. Takagi H, Umemoto T. Atorvastatin, not rosuvastatin, improves cardiac function in heart failure: a meta-analysis of randomized trials. Int J Cardiol. (2012) 155:296-9. doi: 10.1016/j.ijcard.2011.11.079

38. Verberne HJBL, Somsen GA, van Eck-Smit BL. Prognostic value of myocardial 123I metaiodobenzylguanidine (MIBG) parameters in patients with heart failure: a systematic review. Eur Heart J. (2008) 29:114759. doi: 10.1093/eurheartj/ehn113

39. Nishiyama KTT, Tsutamoto T, Yamaji M, Kawahara C, Yamamoto T, Fujii M, et al. Dose-dependent prognostic effect of carvedilol in patients with chronic heart failure: special reference to transcardiac gradient of norepinephrine. Circ J. (2009) 73:2270-5. doi: 10.1253/circj.CJ-09-0456

40. Tsutamoto T, Sakai H, Ibe K, Yamaji M, Kawahara C, Nakae I, et al. Effect of atorvastatin vs. rosuvastatin on cardiac sympathetic nerve activity in non-diabetic patients with dilated cardiomyopathy. Circ J. (2011) 75:21606. doi: 10.1253/circj.CJ-11-0222

41. Millar PJ, Floras JS. Statins and the autonomic nervous system. Clin Sci. (2014) 126:401-15. doi: $10.1042 /$ CS20130332

42. Horwich TB, Middlekauff HR. Potential autonomic nervous system effects of statins in heart failure. Heart Fail Clin. (2008) 4:163-70. doi: 10.1016/j.hfc.2008.01.004

43. Horwich TB, Middlekauff HR, Maclellan WR, Fonarow GC. Statins do not significantly affect muscle sympathetic nerve activity in humans with nonischemic heart failure: a double-blind placebo-controlled trial. J Card Fail. (2011) 17:879-86. doi: 10.1016/j.cardfail.2011. 07.008

44. Demyanets S, Kaun C, Pfaffenberger S, Hohensinner PJ, Rega G, Pammer J, et al. Hydroxymethylglutaryl-coenzyme A reductase inhibitors induce apoptosis in human cardiac myocytes in vitro. Biochem Pharmacol. (2006) 71:132430. doi: 10.1016/j.bcp.2006.01.016

45. Ichihara K, Satoh K. Disparity between angiographic regression and clinical event rates with hydrophobic statins. Lancet. (2002) 359:21958. doi: 10.1016/S0140-6736(02)09098-0

46. Kai T, Arima S, Taniyama Y, Nakabou M, Kanamasa K. Comparison of the effect of lipophilic and hydrophilic statins on serum adiponectin levels in patients with mild hypertension and dyslipidemia: Kinki Adiponectin Interventional (KAI) Study. Clin Exp Hypertens. (2008) 30:530-40. doi: 10.1080/10641960802251925
47. El Said NO, El Wakeel LM, Khorshid H, Darweesh EAG, Ahmed MA. Impact of lipophilic vs hydrophilic statins on the clinical outcome and biomarkers of remodelling in heart failure patients: a prospective comparative randomized study. Br J Clin Pharmacol. (2020). doi: 10.1111/bcp.14695. [Epub ahead of print].

48. Gullestad L, Ueland T, Kjekshus J, Nymo SH, Hulthe J, Muntendam P, et al. Galectin-3 predicts response to statin therapy in the controlled rosuvastatin multinational trial in heart failure (CORONA). Eur Heart J. (2012) 33:22906. doi: 10.1093/eurheartj/ehs077

49. Chitose T, Sugiyama S, Sakamoto K, Shimomura H, Yamashita T, Hokamaki J, et al. Effect of a hydrophilic and a hydrophobic statin on cardiac salvage after ST-elevated acute myocardial infarction - a pilot study. Atherosclerosis. (2014) 237:251-8. doi: 10.1016/j.atherosclerosis.2014.08.053

50. Khurana S, Gupta S, Bhalla H, Nandwani S, Gupta V. Comparison of anti-inflammatory effect of atorvastatin with rosuvastatin in patients of acute coronary syndrome. J Pharmacol Pharmacother. (2015) 6:1305. doi: 10.4103/0976-500X.162011

51. Taylor F, Huffman MD, Macedo AF, Moore TH, Burke M, Davey Smith G, et al. Statins for the primary prevention of cardiovascular disease. Cochrane Database Syst Rev. (2013) 2013:CD004816. doi: 10.1002/14651858.CD009217.pub2

52. Cannon CP, Braunwald E, McCabe CH, Rader DJ, Rouleau JL, Belder R, et al. Intensive versus moderate lipid lowering with statins after acute coronary syndromes. N Engl J Med. (2004) 350:1495-504. doi: 10.1056/NEJMoa 040583

53. Nissen SE, Tuzcu EM, Schoenhagen P, Brown BG, Ganz P, Vogel RA, et al. Effect of intensive compared with moderate lipid-lowering therapy on progression of coronary atherosclerosis: a randomized controlled trial. JAMA. (2004) 291:1071-80. doi: 10.1001/jama.291.9.1071

54. Deedwania P, Stone PH, Bairey Merz CN, Cosin-Aguilar J, Koylan N, Luo $D$, et al. Effects of intensive versus moderate lipidlowering therapy on myocardial ischemia in older patients with coronary heart disease: results of the Study Assessing Goals in the Elderly (SAGE). Circulation. (2007) 115:700-7. doi: 10.1161/CIRCULATIONAHA.106.654756

55. Sakamoto T, Kojima S, Ogawa H, Shimomura H, Kimura K, Ogata $\mathrm{Y}$, et al. Usefulness of hydrophilic vs lipophilic statins after acute myocardial infarction: subanalysis of MUSASHI-AMI. Circ J. (2007) 71:134853. doi: $10.1253 /$ circj.71.1348

56. Lablanche JM, Leone A, Merkely B, Morais J, Alonso J, Santini M, et al. Comparison of the efficacy of rosuvastatin versus atorvastatin in reducing apolipoprotein B/apolipoprotein A-1 ratio in patients with acute coronary syndrome: results of the CENTAURUS study. Arch Cardiovasc Dis. (2010) 103:160-9. doi: 10.1016/j.acvd.2010.01.005

57. Pitt B, Loscalzo J, Monyak J, Miller E, Raichlen J. Comparison of lipidmodifying efficacy of rosuvastatin versus atorvastatin in patients with acute coronary syndrome (from the LUNAR study). Am J Cardiol. (2012) 109:123946. doi: 10.1016/j.amjcard.2011.12.015

58. Sardella G, Lucisano L, Mancone M, Conti G, Calcagno S, Stio RE, et al. Comparison of high reloading rosuvastatin and atorvastatin pretreatment in patients undergoing elective PCI to reduce the incidence of myocardial periprocedural necrosis. The ROMA II trial. Int J Cardiol. (2013) 168:371520. doi: 10.1016/j.ijcard.2013.06.017

59. Izawa A, Kashima Y, Miura T, Ebisawa S, Kitabayashi H, Yamamoto $\mathrm{H}$, et al. Assessment of lipophilic vs hydrophilic statin therapy in acute myocardial infarction - ALPS-AMI study. Circ J. (2015) 79:1618. doi: 10.1253/circj.CJ-14-0877

60. Kim, MC, Ahn, Y, Jang, SY, Cho KH, Hwang SH, Lee MG, et al. Comparison of clinical outcomes of hydrophilic and lipophilic statins in patients with acute myocardial infarction. Korean J Intern Med. (2011) 26:294-303. doi: 10.3904/kjim.2011.26.3.294

61. Bytyçi I, Bajraktari G, Bhatt DL, Morgan CJ, Ahmed A, Aronow WS, et al. Hydrophilic vs lipophilic statins in coronary artery disease: a metaanalysis of randomized controlled trials. J Clin Lipidol. (2017) 11:62437. doi: 10.1016/j.jacl.2017.03.003

62. Zhou Q, Liao JK. Pleiotropic effects of statins. Basic research and clinical perspectives. Circ J. (2010) 74:818-26. doi: 10.1253/circj.CJ-10-0110

63. Bulhak AA, Gourine AV, Gonon AT, Sjoquist PO, Valen G, Pernow J. Oral pre- treatment with rosuvastatin protects porcine myocardium 
from ischaemia/reperfusion injury via a mechanism related to nitric oxide but not to serum cholesterol level. Acta Physiol Scand. (2005) 183:1519. doi: 10.1111/j.1365-201X.2004.01392.x

64. Wolfrum S, Grimm M, Heidbreder M, Dendorfer A, Katus HA, Liao JK, et al. Acute reduction of myocardial infarct size by a hydroxymethyl glutaryl coenzyme A reductase inhibitor is mediated by endothelial nitric oxide synthase. J Cardiovasc Pharmacol. (2003) 41:474-80. doi: 10.1097/00005344-200303000-00017

65. Sahebkar A, Kotani K, Serban C, Ursoniu S, Mikhailidis DP, Jones SR, et al. Statin therapy reduces plasma endothelin-1 concentrations: a meta-analysis of 15 randomized controlled trials. Atherosclerosis. (2015) 241:433-42. doi: 10.1016/j.atherosclerosis.2015. 05.022

66. Eun MY, Jung JM, Choi KH, Seo WK. Statin effects in atrial fibrillationrelated stroke: a systematic review and meta-analysis. Front Neurol. (2020) 11:589684. doi: 10.3389/fneur.2020.589684

67. Pastori D, Baratta F, Di Rocco A, Farcomeni A, Del Ben M, Angelico F, et al. Statin use and mortality in atrial fibrillation: a systematic review and meta-analysis of 100,287 patients. Pharmacol Res. (2021) 165:105418. doi: 10.1016/j.phrs.2021.105418

68. Bonsu KO, Kadirvelu A, Reidpath DD. Statins in heart failure: do we need another trial? Vasc Health Risk Manag. (2013) 9:303-19. doi: 10.2147/VHRM.S44499

69. McKenney JM. Pharmacologic characteristics of statins. Clin Cardiol. (2003) 26 (4 Suppl. 3):III32-38. doi: 10.1002/clc.4960261507

70. Banach M, Rizzo M, Toth PP, Farnier M, Davidson MH, Al-Rasadi K, et al. Statin intolerance - an attempt at a unified definition. Position paper from an International Lipid Expert Panel. Arch Med Sci. (2015) 11:123. doi: 10.5114/aoms.2015.49807

71. Mueller AM, Liakoni E, Schneider C, Burkard T, Jick SS, Krähenbühl $\mathrm{S}$, et al. The risk of muscular events among new users of hydrophilic and lipophilic statins: an observational cohort study. J Gen Intern Med. (2021). doi: 10.1007/s11606-021-06651-6. [Epub ahead of print].
72. Muntean DM, Thompson PD, Catapano AL, Stasiolek M, Fabis J, Muntner P, et al. Statin-associated myopathy and the quest for biomarkers: can we effectively predict statin-associated muscle symptoms? Drug Discov Today. (2017) 22:85-96. doi: 10.1016/j.drudis.2016.09.001

73. Bruckert E, Hayem G, Dejager S, Yau C, Bégaud B. Mild to moderate muscular symptoms with high-dosage statin therapy in hyperlipidemic patients - the PRIMO study. Cardiovasc Drugs Ther. (2005) 19:40314. doi: 10.1007/s10557-005-5686-z

74. Climent E, Benaiges D, Pedro-Botet J. Statin treatment and increased diabetes risk. Possible mechanisms. Clin Investig Arterioscler. (2019) 31:22832. doi: $10.1016 /$ j.arteri.2018.12.001

75. Fong CW. Statins in therapy: understanding their hydrophilicity, lipophilicity, binding to 3-hydroxy-3-methylglutaryl-CoA reductase, ability to cross the blood brain barrier and metabolic stability based on electrostatic molecular orbital studies. Eur J Med Chem. (2014) 85:661-74. doi: 10.1016/j.jejmech.2014.08.037

76. Mach F, Ray KK, Wiklund O, Corsini A, Catapano AL, Bruckert E, et al. Adverse effects of statin therapy: perception vs. the evidence - focus on glucose homeostasis, cognitive, renal and hepatic function, haemorrhagic stroke and cataract. Eur Heart J. (2018) 39:2526-39. doi: 10.1093/eurheartj/ehy182

Conflict of Interest: The authors declare that the research was conducted in the absence of any commercial or financial relationships that could be construed as a potential conflict of interest.

Copyright $\odot 2021$ Climent, Benaiges and Pedro-Botet. This is an open-access article distributed under the terms of the Creative Commons Attribution License (CC BY). The use, distribution or reproduction in other forums is permitted, provided the original author(s) and the copyright owner(s) are credited and that the original publication in this journal is cited, in accordance with accepted academic practice. No use, distribution or reproduction is permitted which does not comply with these terms. 